\title{
New classification of peripheral retinal vascular changes in sickle cell disease
}

\author{
Alan D Penman, John F Talbot, Elaine L Chuang, Peter Thomas, Graham R Serjeant, \\ Alan C Bird
}

\begin{abstract}
The systemic complications of homozygous sickle cell disease (SS) are more severe than in sickle cell haemoglobin $\mathrm{C}(\mathrm{SC})$ disease, and yet visual loss due to proliferative retinopathy is more common in the latter. This anomaly is unexplained. It is believed that proliferative disease occurs in response to closure of the peripheral retinal vasculature, yet a systematic longitudinal survey of the peripheral retinal vascular bed has not been undertaken. In the Jamaica Sickle Cohort study all subjects are scheduled to receive annual ocular examination and fluorescein angiography. The results have now been analysed in subjects with SS and SC disease using a new classification system based on a comparison of the peripheral retinal vascular bed with that recorded in the cohort with normal haemoglobin (AA) genotype. The vascular patterns could be classified as qualitatively normal (type I) or abnormal (type II). An abnormal vascular pattern was identified more commonly with age, in a significantly larger proportion of subjects with SC than SS disease, and was associated with the development of proliferative disease. In order to establish the dynamics of change, the angiograms were analysed in the 18 subjects (24 eyes) who developed proliferative disease. It is shown that a qualitatively normal vascular pattern may be retained despite loss of capillary bed and posterior displacement of the vascular border. A border which is quali-

cell diseases is vascular proliferation in the peripheral retina (proliferative sickle retinopathy, PSR), which may lead to vitreous haemorrhage or retinal detachment. ${ }^{1}$ The development of PSR is believed to occur in response to progressive peripheral retinal vascular closure, and centripetal recession of the peripheral margin of perfusion. This process has been described,,$^{2-4}$ and extensive remodelling of the peripheral capillary bed has been reported in adults. ${ }^{5} \mathrm{~A}$ sequence of events was proposed by Goldberg in $1972,{ }^{6}$ and later modified by Condon and Serjeant. ${ }^{7}$ However, the relation between peripheral vascular closure and PSR is not well understood. Although vascular obstruction would be predicted to be more common in homozygous sickle cell (SS) disease than in sickle cell haemoglobin C (SC) disease on the basis of systemic involvement, ${ }^{8}$ peripheral retinal non-perfusion and PSR are more common in adults with SC disease. ${ }^{19} 10$

In an attempt to explain this dilemma we have documented the evolution of sickle retinopathy by undertaking serial fluorescein angiograms in a cohort of children with SS and SC genotypes. The patterns of the peripheral retinal vasculature were characterised and compared with those seen in subjects with a normal (AA) haemoglobin genotype. ${ }^{11}$ It appears that an abnormal pattern of the peripheral retinal vasculature is more common in SC than SS disease, and in addition correlates with the subsequent development of PSR.
\end{abstract} tatively abnormal does not revert to normal, and once abnormal, continuous evolution may occur before development of proliferative lesions. The peripheral border of the retinal vasculature was too peripheral to photographed in 13 of the 24 eyes before it becoming qualitatively abnormal. It is concluded that a normal border, if posterior, results from gradual modification of the capillary bed and indicates low risk of proliferative disease. A qualitatively abnormal vascular border occurs as a radical alteration of retinal perfusion in subjects in whom little modification of the vascular bed occurred before the event, and signals risk of proliferative disease. This classification system is useful in identifying the likelihood of threat to vision in young Jamaicans with sickle cell disease, and the higher frequency of proliferative retinopathy in SC can be explained by the higher prevalence of a qualitatively abnormal peripheral retinal vasculature.

(Br F Ophthalmol 1994; 78: 681-689)

The major threat to vision in patients with sickle

\section{Subjects and methods}

\section{THE JAMAICAN SICKLE COHORT}

Between 1973 and 1981, 315 children with SS disease, 173 with SC disease, and 250 age/sexmatched controls with normal haemoglobin (AA) genotype, were recruited to the study. ${ }^{12}{ }^{13}$ The protocol of the ocular study called for annual ophthalmoscopic examinations of the sickle cell children aged 5 years and over, and fluorescein angioscopy and/or angiography over the age of 6 years.

The ophthalmic component of the cohort study is now in its 12 th year, and a very large data base has accumulated, with clinical and ophthalmic information in 392 subjects, and over 2000 fluorescein angiograms. Serial angiography of corresponding retinal areas is available on a large number of subjects.

\section{STUDY DESIGN}

The ophthalmic records and fluorescein angiograms performed on all eligible subjects with SS

Eye Hospital, City Road,

Accepted for publication

5 May 1994 


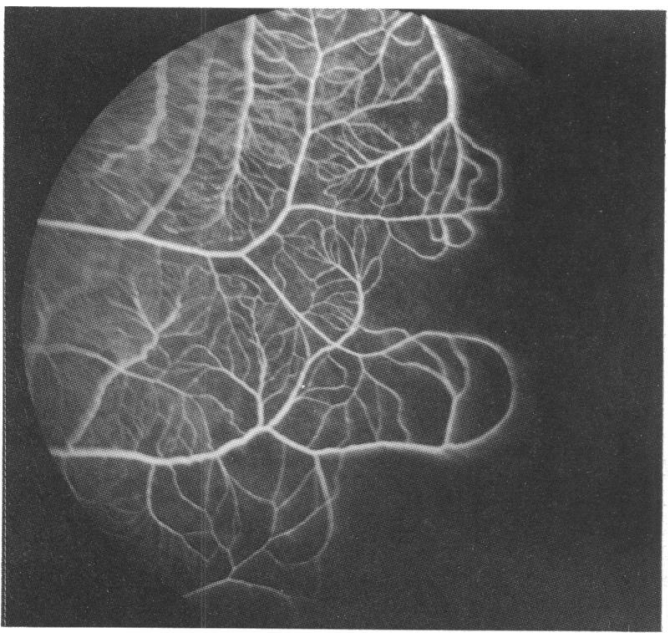

Figure 1 Left eye of 15-year-old male with $\mathrm{Hb} S \mathrm{~S}$ disease. Type I border: continuous arteriovenous loops with progressive thinning of capillary bed towards periphery.

or SC disease in the Jamaican Sickle Cell Cohort Study from 1981 to 1992 were reviewed. The angiograms were classified, and the results assessed in relation to genotype, age, and the subsequent evolution of disease.

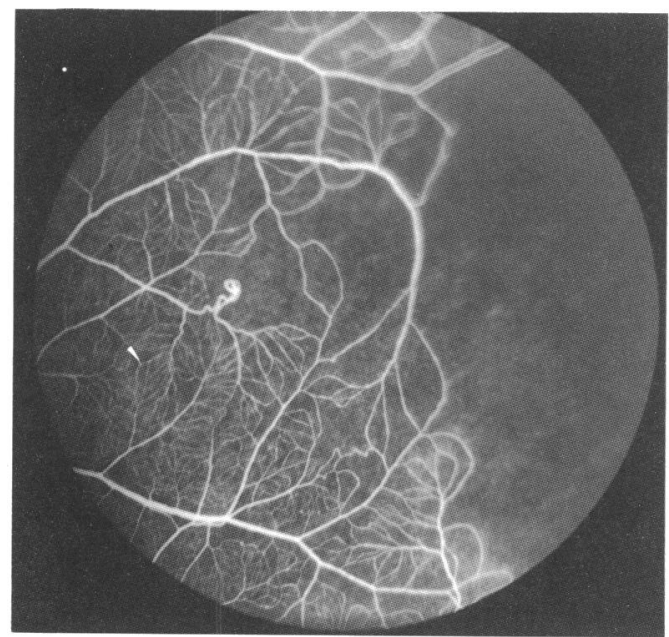

Figure 2 Left eye of 14-year-old male with $\mathrm{Hb}$ SS disease. Type I border: continuous arteriovenous loops with irregula large capillary free areas and small vascular anomaly.

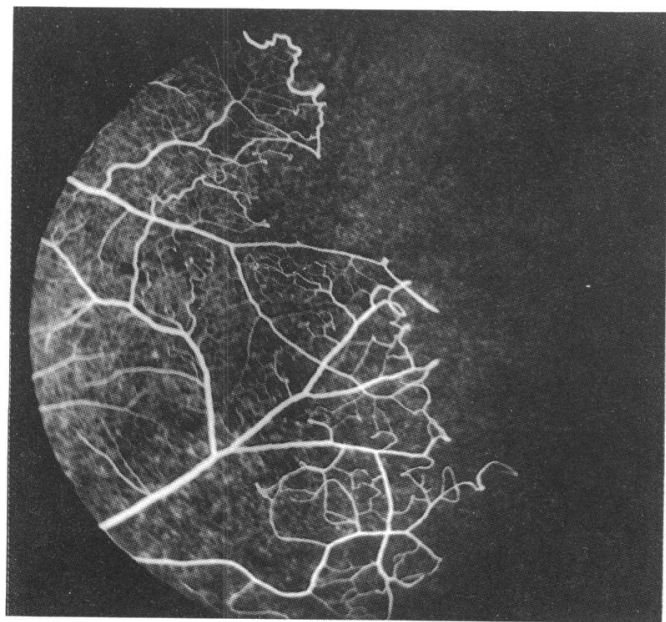

Figure 3 Left eye of 10-year-old male with $\mathrm{Hb}$ SC disease showing a type II a border: irregular margin without arteriovenous loops or attenuation of capillary density. Capillary stumps extend into non-perfused retina.

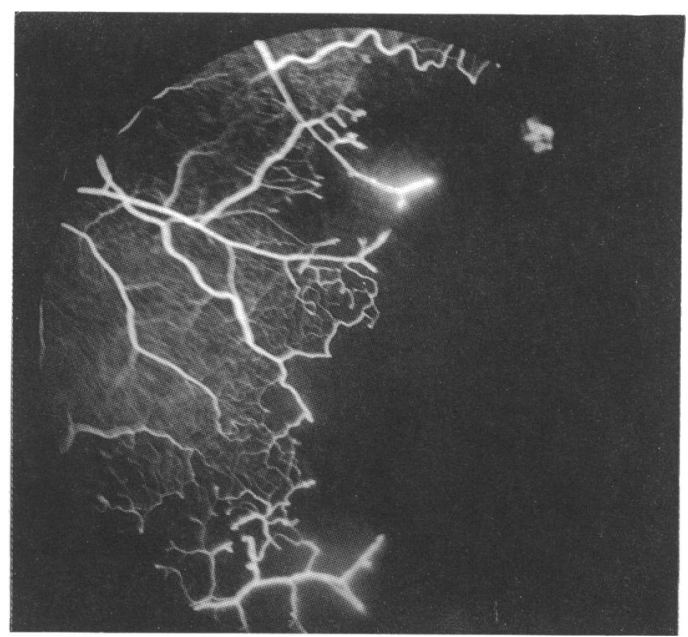

Figure 4 Left eye of 11-year-old male with SC disease showing a type II a pattern with hyperfluorescence of capillaries extending into the avascular retina.

METHODS

At each annual ocular examination the visual acuity was measured, and retinal drawings indicated the number and position of haemorrhages, chorioretinal scars, retinal schisis cavities, and PSR lesions. Fluorescein angioscopy and angiography were undertaken unless there was a specific contraindication. A bolus dose of 2-4 ml of $20 \%$ sodium fluorescein was injected intravenously, and the circumferential extent of the visible peripheral margin of retinal perfusion recorded by angioscopy. The retinal vasculature was photographed with a Zeiss fundus camera (Zeiss, Oberkochen, Germany) using Ilford FP4 black and white film. Every effort was made to photograph the peripheral margin of the vascular bed over $90^{\circ}$ of the temporal periphery, and the posterior pole of each eye. In those in whom less than $360^{\circ}$ of the peripheral margin had been seen previously, fluoroscopy was undertaken initially followed by photography. If the whole of the margin had been seen previously in both eyes, photography was performed first.

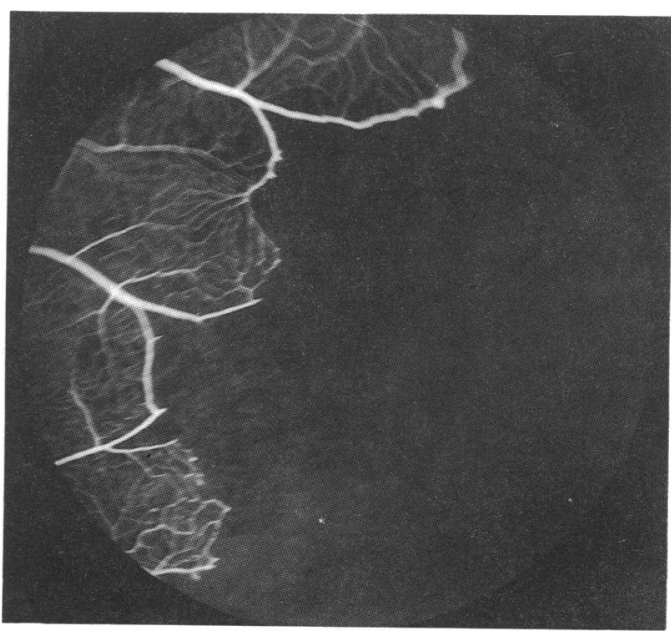

Figure 5 Left eye of 16-year-old female with $\mathrm{Hb}$ SC disease. Type IIb border: irregular border without continuous arteriovenous loops or attenuation of capillary density. No capillary stumps extend into non-perfused retina. 


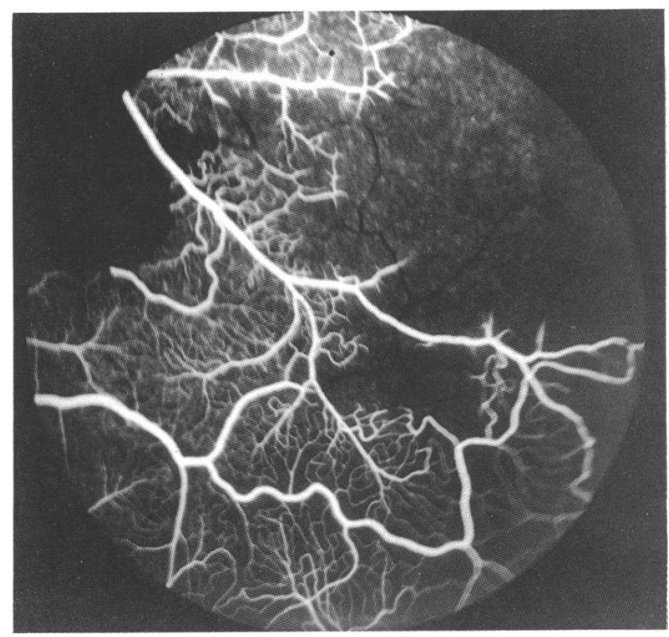

Figure 6 Left eye of a 10-year-old male with $\mathrm{Hb}$ SC disease showing obstruction of a blood vessel. The presence of a hypofluorescence column continuous with the cessation of fluorescence within the vessel implies recent occlusion. The capillary bed appears to conform with a type II, and yet reperfusion may occur such that this border was deemed unclassifiable.

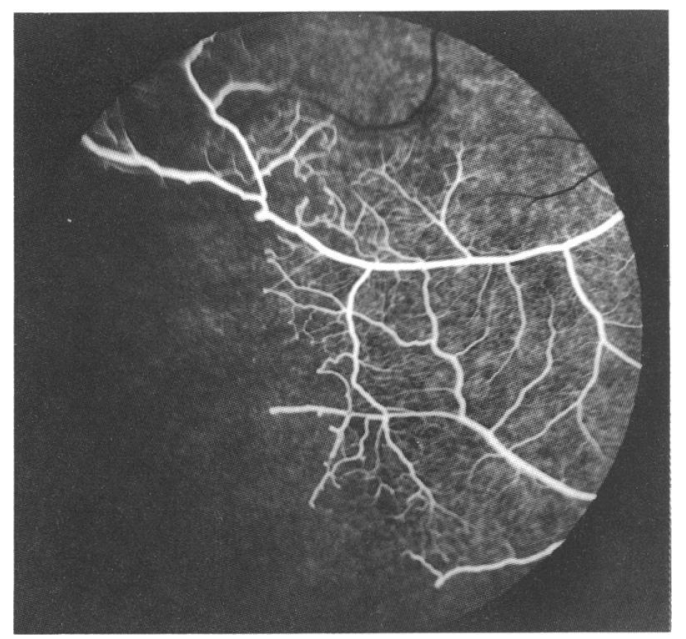

Figure 7 Left eye of 10-year-old male with $\mathrm{Hb} S \mathrm{SC}$ disease. Recently obstructed vessels appear as hypofluorescent lines, but the appearance (IIa) of the margin has not been altered by this event.

\section{Classification of angiographic patterns}

The proposed system of classification characterises the changes in the peripheral retinal

Table 1 Abnormal vascular border in different genotypes (no $(\%)$ ) according to most abnormal pattern recorded

\begin{tabular}{lcc}
\hline Pattern type & SC disease & SS disease \\
\hline I & $48(32)$ & $210(86)$ \\
IIa & $57(38)$ & $4(2)$ \\
IIb & $37(25)$ & $17(7)$ \\
Other & $6(4)$ & $13(5)$ \\
Total & 148 & 244 \\
\hline
\end{tabular}

Table 2 Correlation of abnormal vascular borders with age and with genotype (no (\%))

\begin{tabular}{|c|c|c|c|c|c|c|}
\hline \multirow[b]{2}{*}{$\begin{array}{l}\text { Age } \\
\text { (years) }\end{array}$} & \multicolumn{3}{|l|}{$S C$ disease } & \multicolumn{3}{|l|}{ SS disease } \\
\hline & $\begin{array}{l}\text { Readable } \\
\text { angiograms }\end{array}$ & $I I a$ & $I I b$ & $\begin{array}{l}\text { Readable } \\
\text { angiograms }\end{array}$ & $I I a$ & $I I b$ \\
\hline $\begin{array}{r}8 \\
9 \\
10 \\
11 \\
12 \\
13 \\
14 \\
15 \\
16 \\
17\end{array}$ & $\begin{array}{r}52 \\
92 \\
117 \\
145 \\
150 \\
125 \\
121 \\
113 \\
87 \\
54\end{array}$ & $\begin{array}{r}9(17) \\
14(14) \\
18(15) \\
29(20) \\
35(23) \\
33(26) \\
32(26) \\
33(29) \\
34(39) \\
22(42)\end{array}$ & $\begin{array}{l}15(29) \\
27(29) \\
32(27) \\
42(29) \\
48(32) \\
37(30) \\
40(33) \\
34(30) \\
19(22) \\
12(22)\end{array}$ & $\begin{array}{r}171 \\
237 \\
235 \\
263 \\
221 \\
212 \\
163 \\
141 \\
118 \\
82\end{array}$ & $\begin{array}{l}0 \\
0 \\
0 \\
0 \\
0 \\
0 \\
0 \\
1 \\
2 \\
1\end{array}$ & $\begin{array}{c}3(2) \\
5(2) \\
8(3) \\
10(4) \\
12(5) \\
13(6) \\
12(7) \\
10(7) \\
13(11) \\
11(13)\end{array}$ \\
\hline
\end{tabular}

Table 3 The number of eyes with readable angiograms on 2 successive years which converted from a type I to a type II border in which a type I border assessed according to age

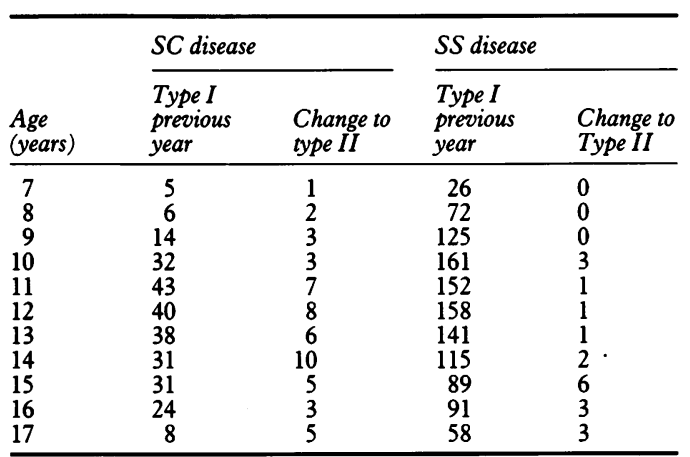

Table 4 Symmetry between eyes in the pattern of the peripheral vasculature in SC disease (kappa $=0 \cdot 6 ; S E$ 0.072 )

\begin{tabular}{llrr}
\hline \multirow{2}{*}{$\begin{array}{l}\text { Right eye } \\
\text { border type }\end{array}$} & \multicolumn{3}{l}{ Left eye border type } \\
\cline { 2 - 4 } & $I$ & $I I$ & $I I I$ \\
\hline I & 38 & 3 & 8 \\
II & 9 & 29 & 7 \\
III & 6 & 6 & 23 \\
\hline
\end{tabular}

vasculature, and distinguishes normal vascular patterns from abnormal on the fluorescein angiogram. The normal pattern had been established in a study of the subjects with haemoglobin AA within the cohort. ${ }^{11}$ Each eye was designated as conforming to a pattern which was indistinguishable qualitatively from normal (type I), abnormal (type II), or to a category implying that such a designation could not be made. If the vascular border in an eye showed normal and abnormal patterns in different regions the eye was classified according to the region which was most abnormal.

Type I. This pattern was qualitatively similar to normal. ${ }^{11}$ It was required that the capillaries became gradually less dense in distribution and longer as the border was approached, and the border was smooth and formed of arteriovenous loops of varying length (Fig 1). Additional features were allowed within this type, including avascular lacunae within the peripheral capillary bed, hairpin loops, or tortuous vessels (Fig 2).

Type II. The peripheral retinal vasculature differed from the normal pattern because a dense capillary bed existed up to the margin of perfusion with abrupt terminations of small or medium calibre vessels creating an irregular or 'moth eaten' appearance to the border.

Type II presented two morphological patterns. In some cases there were capillary 'buds' or 'stumps' extending from the border of the vasculature into the non-perfused retina which were sometimes hyperfluorescent or even leaked fluorescein slightly (Figs 3, 4). In some cases, the capillary 'buds' or 'stumps' showed bifurcations which simulated the capillary pattern seen when there is active reperfusion of recently infarcted retina. ${ }^{14} \mathrm{~A}$ border with this feature was classified as IIa, and otherwise as IIb (Fig 5).

Type III. The pattern was indeterminate because recent acute arteriolar occlusion involving the vascular border had given rise to a type II pattern, but which may have reverted to normal following subsequent reperfusion of the vascular 
Table 5 The border type compared posterior position of vascular margin shows that a significantly higher percentage of type II a and type IIb borders had a posterior location than type I in SC disease (no (\%)) $\left(R E \chi^{2}=41 \cdot 6, d f=2, p<0.001 ; L E \chi^{2}=30 \cdot 4, d f=2\right.$, $p<0.001)$. The numbers in $S S$ disease were too small to reach significant levels

\begin{tabular}{llllllll}
\hline & \multicolumn{3}{l}{$\begin{array}{l}\text { SC disease } \\
\text { Border classification }\end{array}$} & & & \multicolumn{2}{l}{$\begin{array}{l}\text { SS disease } \\
\text { Border classification }\end{array}$} \\
\cline { 2 - 4 } Classification & $I$ & $I I a$ & $I I b$ & & $I$ & $I I a$ & $I I b$ \\
\hline Posterior & $30(30)$ & $78(87)$ & $55(76)$ & & $157(40)$ & 3 & $17(71)$ \\
Not posterior & $70(73)$ & $11(13)$ & $17(24)$ & & $235(60)$ & 1 & $7(29)$ \\
Total & 100 & 85 & 72 & & 392 & 4 & 24 \\
\hline
\end{tabular}

Table 6 Classification of border type compared with the extent of the vascular margin seen by fluoroscopy at the time of the last angiogram. A significantly higher proportion of a type II border had $>270^{\circ}$ of the periphery seen than type I in $S C$ disease $\left(R E \chi^{2} d=17 \cdot 5, d f=2, p<0 \cdot 001 ; L E \chi^{2}=26 \cdot 1\right.$, $d f=2, p<0.001)$ and for $S S$ disease $(p=0.053$ for the $R E$ and 0.060 for the LE, Fisher's exact test)

\begin{tabular}{|c|c|c|c|c|c|c|}
\hline \multirow{2}{*}{$\begin{array}{l}\text { Margin } \\
\text { extent }\end{array}$} & \multicolumn{3}{|c|}{$\begin{array}{l}\text { SC disease } \\
\text { Border classification }\end{array}$} & \multicolumn{3}{|c|}{$\begin{array}{l}\text { SS disease } \\
\text { Border classification }\end{array}$} \\
\hline & $I$ & $I I a$ & $I I b$ & $I$ & $I I a$ & $I I b$ \\
\hline $\begin{array}{l}<180^{\circ} \\
<270^{\circ} \\
>270^{\circ} \\
\text { Total }\end{array}$ & $\begin{array}{r}11 \\
58 \\
43 \\
112\end{array}$ & $\begin{array}{r}1 \\
17 \\
68 \\
86\end{array}$ & $\begin{array}{r}1 \\
17 \\
55 \\
73\end{array}$ & $\begin{array}{r}31 \\
186 \\
207 \\
424\end{array}$ & $\begin{array}{l}0 \\
1 \\
3 \\
4\end{array}$ & $\begin{array}{r}0 \\
5 \\
19 \\
24\end{array}$ \\
\hline
\end{tabular}

Table 7 Vascular obstruction in eyes of SC subjects in which change was recorded from type I to type II (index eye) compared with eyes of $S C$ subjects and $S S$ subjects in which the border retained type I characteristics as pairs matched as to age of the subject, number of visits, and age at the time of the last visit. Using McNemar's test (paired $\chi^{2}$ ), index patients were different from the $S C$ comparison group $\left(\chi^{2}=11.03, d f=1, p<0.001\right)$, and the $S S$ comparison group $\left(\chi^{2}=13 \cdot 8, d f=1, p<0 \cdot 001\right)$. The $S C$ and $S S$ comparison groups were not different $\left(\chi^{2}=0.00, d f=1, p=1 \cdot 0\right)$

\begin{tabular}{llll}
\hline & $\begin{array}{l}\text { Index } \\
\text { eye }\end{array}$ & $\begin{array}{l}\text { SC } \\
\text { comparison }\end{array}$ & $\begin{array}{l}\text { SS } \\
\text { comparison }\end{array}$ \\
\hline No obstruction & 22 & 44 & 43 \\
Old obstruction & 10 & 6 & 4 \\
Recent obstruction & 29 & 11 & 14 \\
Total & 61 & 61 & 61 \\
\hline
\end{tabular}

bed. The recent nature of the obstruction was identified by the presence of an abrupt cessation of the intravascular dye column of an arteriole with a hypofluorescent column extending beyond it caused by absorption of light by intravascular blood or altered blood products (Fig 6). An eye was not classified as type III if other regions of the border could be classified as type II (Fig 7).

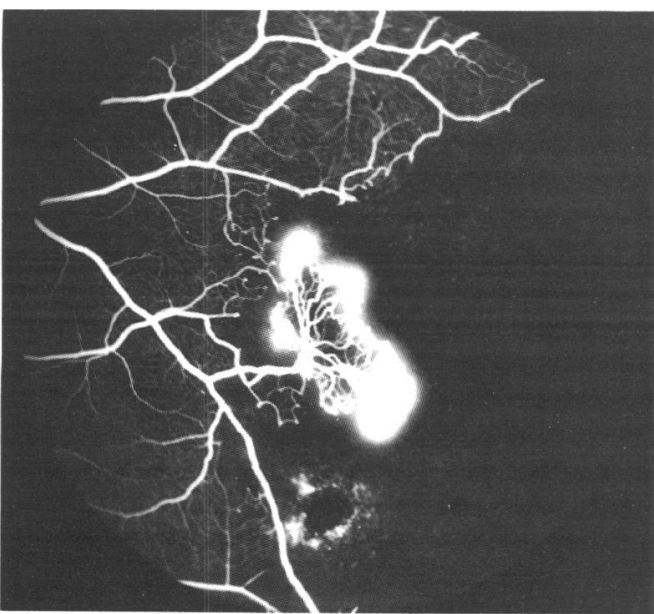

Figure 8 The left eye of a 9-year-old male with $\mathrm{Hb}$ SC disease. Proliferative sickle retinopathy in association with type II a border.
The vascular border was designated as unreadable if the edge was too peripheral to be photographed, the photographs were blurred owing to astigmatic aberration, or the fluorescence was too faint.

\section{Other angiographic features}

Evidence of previous acute arteriolar occlusion in any frame was recorded, whether or not the vascular border was involved. A distinction was made between vessels which did or did not continue as a hypofluorescent linear column. The presence of this feature was believed to signify a recent occlusion and, therefore, the possibility of subsequent reperfusion.

The extent of non-perfused retina was assessed according to its posterior displacement and the circumferential extent of the vascular margin that could be seen by fluoroscopy. ${ }^{2}$ The presence of a posterior location of the border was designated on fluoroscopy if the vascular border was post-equatorial.

\section{Scoring procedure}

Positive and negative transparencies were examined under magnification, and the classification of the vascular border was limited to the temporal retina. Up to 1991, angiograms of each eye for

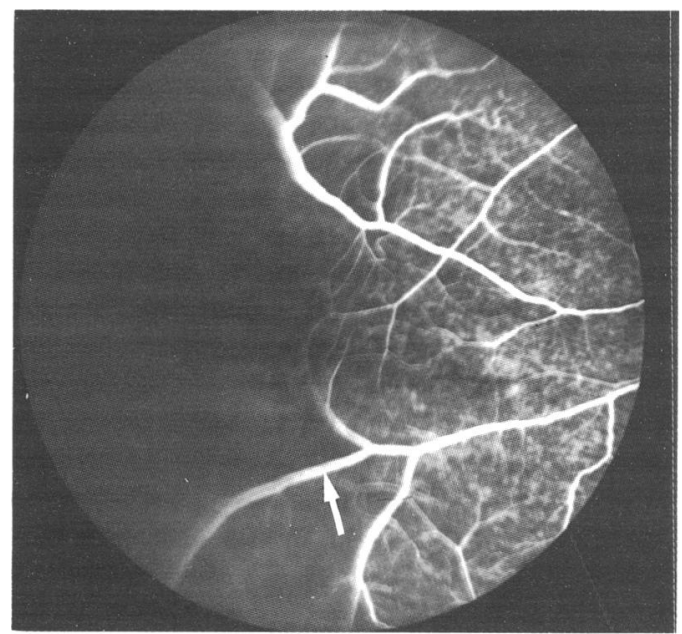

Fig $9 A$

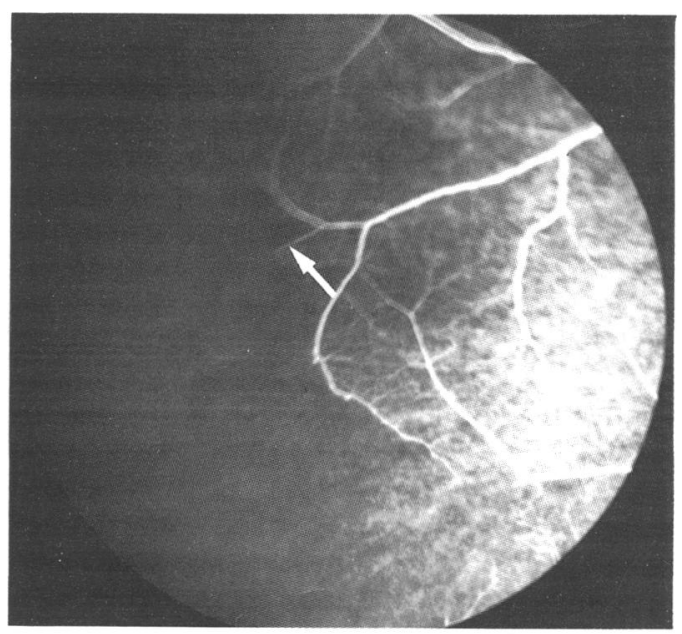

Fig $9 B$

Figure 9 Right eye of a 10-year-old male with SC disease with a type I border $(A)$. Within 1 year there is a change in the vasculature with loss of a large peripheral loop (arrow) but without change in the designation $(B)$. 


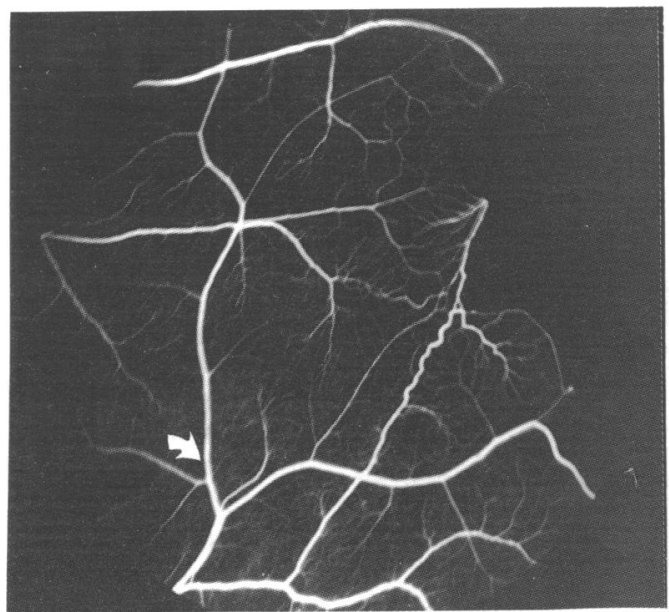

Fig 10A

Figure 10 Left eye of a 16-year-old male with SC disease designatea type $1(A)$. One year later there was a major change of the vascular bed with loss of capillaries and vascular obstruction (arrow) $(B)$. However, the edge retains type I characteristics.

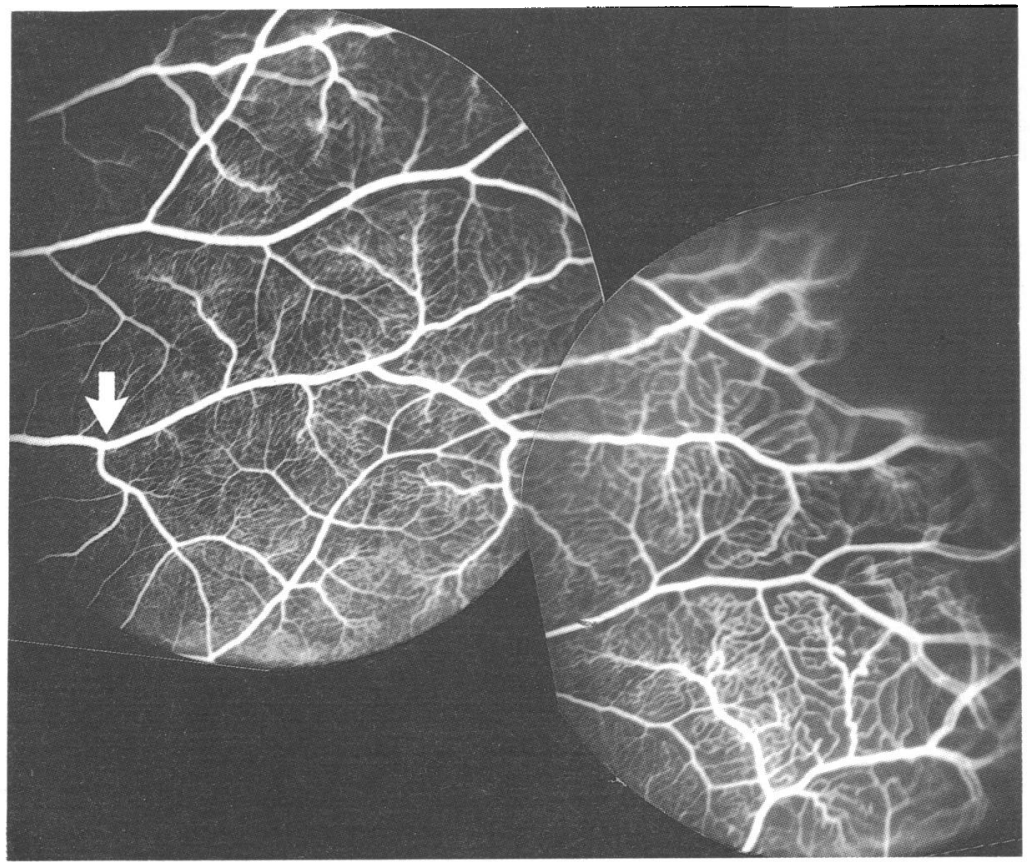

Fig $11 \mathrm{~A}$

every year were scored according to the proposed classification system. The four observers were masked from one another and from the genotype of the subject. There was no masking of the angiogram scores of that subject in previous years. Those angiograms for which there was not universal agreement were reviewed by the group as whole, and a final coding agreed upon. A measure of interobserver agreement was calculated using kappa statistic. Good reliability was established, and the proposed coding system was shown to be practicable. For 1992, two observers classified the marging independently, being masked as to the previous classification of the angiogram, and a third arbitrated in the case of disagreement.

\section{Correlates of classification}

The data were analysed to ascertain whether or not correlations existed between the type of vascular pattern and age, sex, and genotype of the subject. Comparison was also made with certain retinal features:

(a) The circumferential extent of visible peripheral retinal vascular non-perfusion as

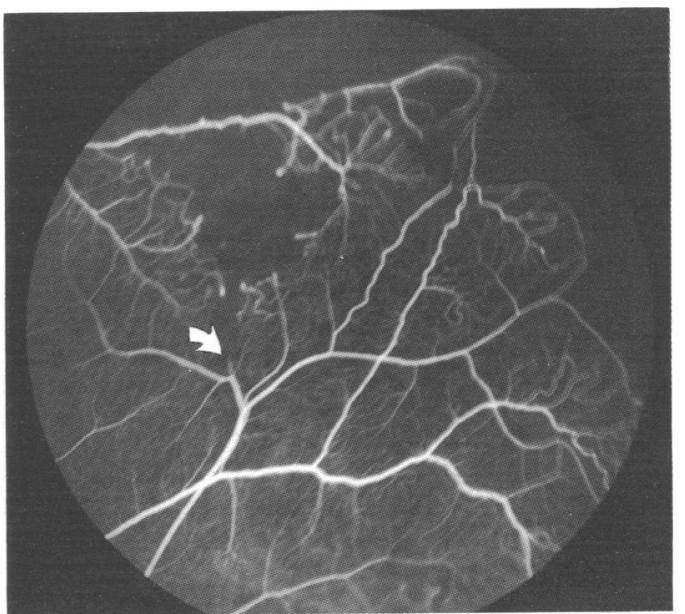

Fig $10 B$

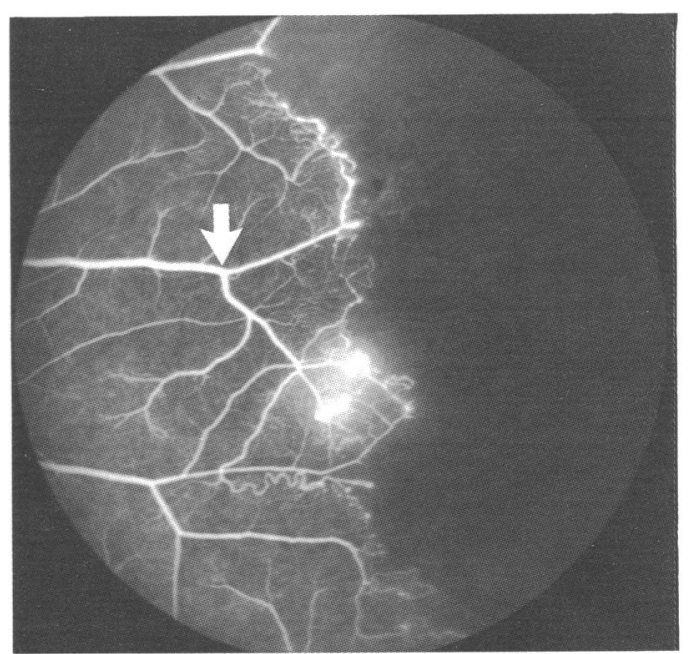

Fig $11 B$

Figure 11 Left eye of male with SS disease at 14 years had a type 1 border $(A)$. Two years later there was a major recession of the border which now had type II characteristics (B). Corresponding arterial divisions have been marked with an arrow.

judged by fluoroscopy.

(b) The posterior location of the vascular margin.

(c) The number of retinal haemorrhages, chorioretinal scars, and schisis cavities.

(d) The presence of vessel occlusions. Two matched pair studies were performed. In the first, subjects with SC disease in whom a type I border changed to a type II were matched by genotype, age in years, and number of visits $( \pm 1)$ with an individual with persistent type I border. In the second, each SC subject with a type II border was also paired with one with SS disease who retained a type I border using the same criteria. The pairs were compared with respect to the number with a recorded vascular obstruction, the number of obstructive events detected, and a distinction was made between acute and old obstruction.

(e) The presence of PSR.

Dynamics of change

The serial angiograms of the 24 eyes of 18 subjects in which PSR developed during the period of the cohort study were examined for 
change between annual visits. 4 ll but one of the subjects had SC disease.

\section{Results}

Of the 308 SS subjects and the 173 SC subjects

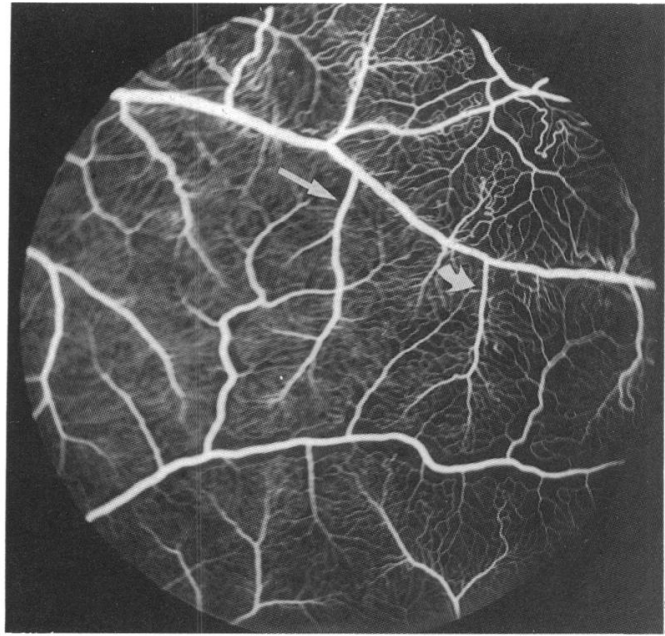

Fig $12 \mathrm{~A}$

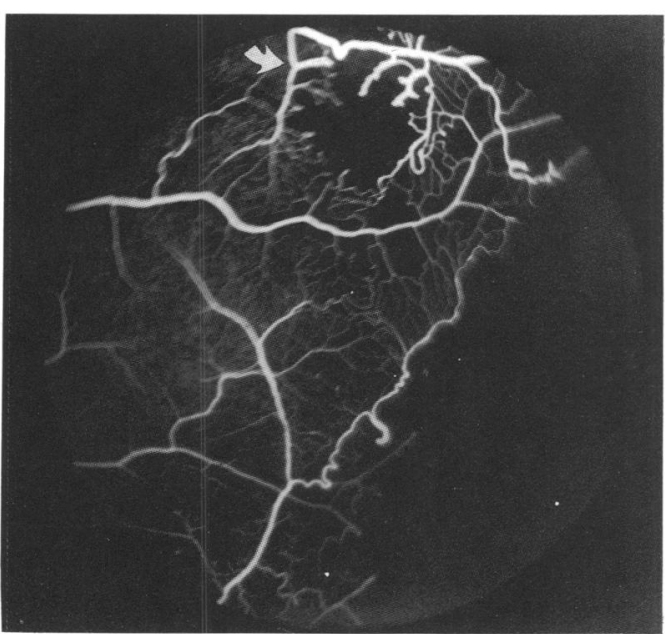

Fig $12 B$

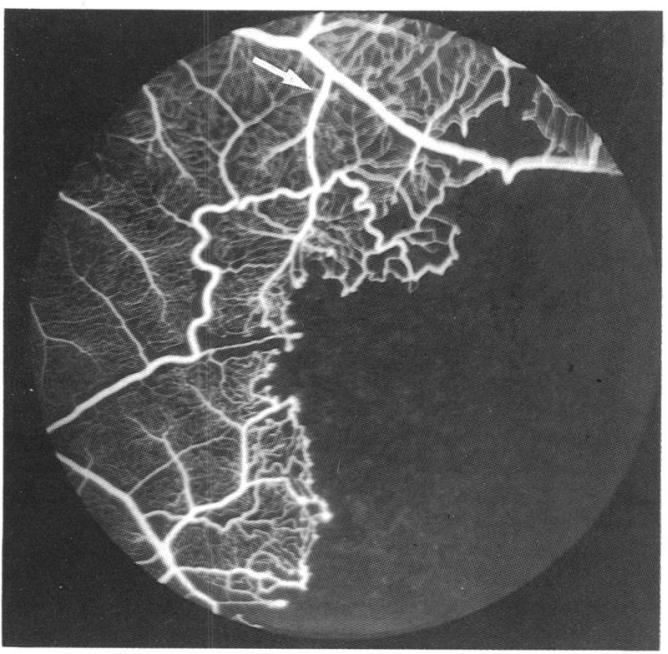

Fig $12 C$

Figure 12 Left eye of 10-year-old female with SC disease at which time the edge was not photographed $(A)$. Within I year the edge had type II characteristics (corresponding vessels marked with a curved arrow) $(B)$. A further year later there was major recession of the edge (corresponding vessels are marked with a straight arrow) $(C)$. recruited to the study at birth, 260 and 154 respectively were available for examination at the age of 5 years. Of those not seen 68 were either lost to review soon after birth, died, or emigrated. Four were unsuitable for study because of other eye disease and 17 did not attend an annual review. In each year, between $93 \%$ and $96 \%$ ascertainment was achieved of those known to be available for study. Photographs of the vascular border could be classified at least once as normal or abnormal in $\mathbf{3 7 3}$ of the subjects. In the remainder the border was either too peripheral for it to be photographed, or no designation as normal or abnormal could be made (type III or unclassifiable).

Of the 390 subjects categorised up to 1991, there was universal agreement on the assignment of both eyes for all years of study between all four readers in 336. The agreement between pairs of observers for the distinction between normal (type I) and abnormal (type II) (six comparisons) gave kappa values between 0.79 and 0.71 . There was more disagreement as to the distinction between IIa and IIb although the lowest kappa value for this was $0 \cdot 64$.

When compared using the unpaired $t$ test, the SC and SS groups were similar in terms of the mean number of ophthalmic examinations (5.9 $(\mathrm{SD} 2 \cdot 5)$ and $5 \cdot 8(2 \cdot 5)$ respectively; $\mathrm{p}=0.87)$, the number of years between the first and last visits $(5 \cdot 8(2 \cdot 8)$ and $5 \cdot 7(2 \cdot 8)$ respectively; $p=0 \cdot 76)$ and the number of angiograms in which the border could be classified as normal or abnormal (4.6 $(2 \cdot 4)$ and $4.9(2 \cdot 6)$ respectively; $p=0.31)$. In SC subjects the prevalence of pattern IIa border increased with age $\left(\chi^{2}\right.$ for trend $\left.=29.3, p<0.01\right)$, and a type II border was considerably more common in SC than in SS disease (Tables 1, 2). This was not influenced by sex in either genotype $\left(\chi^{2}\right.$ test overall $\left.=0.73, p=0.69\right)$. In the majority of cases a change from normal to abnormal was recorded although in some an abnormal border was seen on the first angiogram in which the border was photographed. The age of conversion was lower in SC disease than SS (Table 3). The border classification tended to be similar for both eyes of a single individual, although asymmetry was not uncommon (Table 4).

The borders classified as II were more posterior and had a greater circumference of the border seen than those classified as type I, although a posterior position allowing full visualisation of $360^{\circ}$ of the border was not exclusive to fundi with a type II designation (Table 5,6 ).

The number with documented vascular obstruction, both acute and long term, and the number of recorded occluded vessels for each year recorded was greater in those who developed an abnormal border, although such events were also seen in those in whom the border remained normal (Table 7).

Proliferative retinopathy was been seen in only 24 eyes of 18 subjects (17 with $\mathrm{Hb}$ SC and one with $\mathrm{Hb}$ SS), and was always associated with a type II border (23 IIa and one IIb) (Fig 8). Serial photographs of the same area were not available in one of these subjects. In this case the border was too peripheral to be photographed before the onset of a type II border, and at the three annual visits thereafter either the same area was not 
Figure 13 Right eye of male aged 12 years with $S C$ disease showing a type II a border $(A)$. Within I year there was loss of a major peripheral loop $(B)$

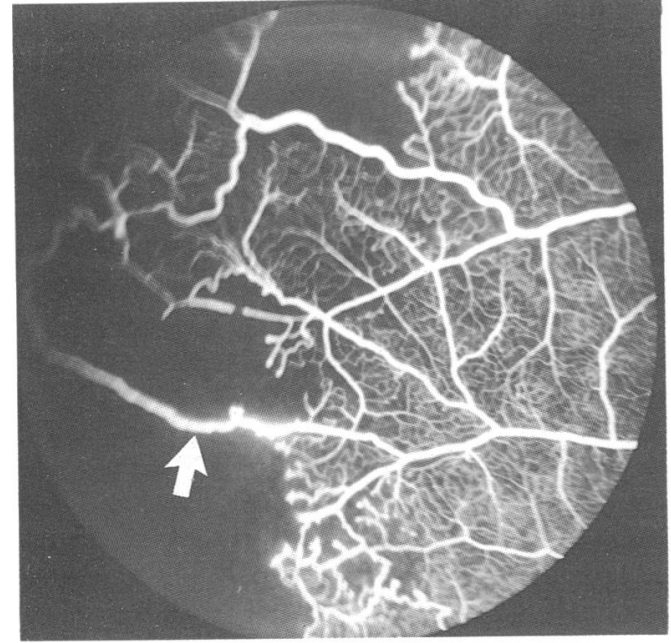

Fig $13 A$

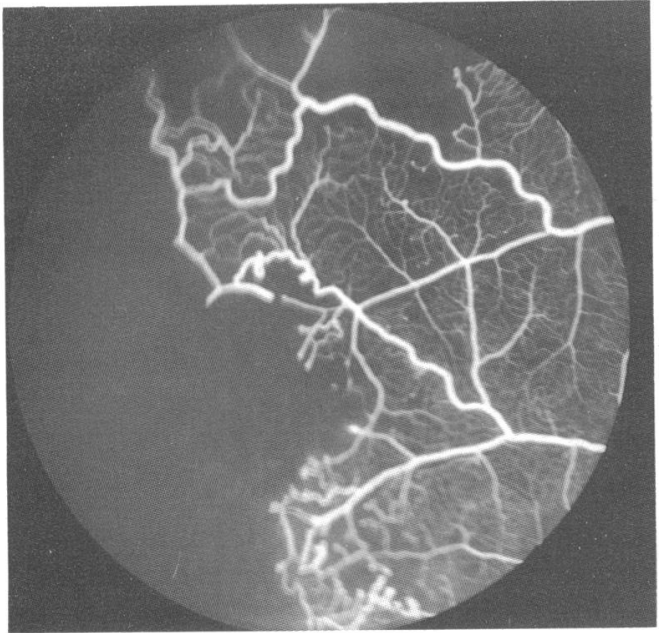

Fig $13 B$

photographed or the extent of remodelling of the vasculature prevented recognition of the same area. In the remaining 23 eyes, the evolution of change in the peripheral vasculature varied greatly from one subject to another. In 11 eyes of nine subjects a type I border was recorded at two or more (range 2-7) annual visits before a type II being identified. In three eyes changes in the vascular bed were identified without there being an alteration of category (Figs 9, 10). In eight eyes the border was stable for as long as 6 years before conversion to a type II border. In the remaining 12 eyes good angiograms were obtained but the border was too peripheral to be photographed before demonstration of a type II border, and after conversion it was possible to identify that the new border corresponded with an area photographed that had been within the vascular bed (Figs 11, 12).

In 18 eyes of 14 subjects serial photographs were available of the same area at two or more annual visits (range 2-7) after a type II border had been recognised before development of PSR. In all but four eyes there was progressive change of the vascular bed (Figs 12, 13). In the remaining five eyes, PSR was recorded at the same examination or within 1 year of demonstration of a type II border (Fig 14).

\section{Discussion}

The peripheral retinal vasculature in sickle cell disease presents different patterns which correlate with genotype, and indicates the risk of the developing visually threatening disease.

Interobserver agreement, as measured by kappa statistic, was good such that the classification system appears to be reliable and practicable. The main area of disagreement was in the subclassification of abnormal patterns rather than in the distinction between normality and abnormality.

There are clear limitations inherent in this cohort study when seeking incidence data, in that the ophthalmic findings are recorded only once a year. For example, multiple events may occur during any year which would be recorded only as a single event, and vascular obstruction followed by full restoration of the circulation would not be detected; such an event has been well described. ${ }^{15}$ In addition, since only $90^{\circ}$ of the peripheral retina was photographed the survey is far from complete. Alterations in the retinal vasculature outside this area were not recorded routinely and were ignored in this study when available. Nevertheless, from these observations certain general conclusions can be drawn concerning the implications of different vascular patterns and the dynamics of change in the peripheral retinal circulation.

Although the type I border is qualitatively similar to that seen in normal subjects this does not imply that the type I border is unmodified by disease. The posterior location and the extent of the visible border were apparently different from normal, ${ }^{11}$ and it was a strong impression that the type I border in sickle cell disease was much easier to photograph than in subjects with normal haemoglobin (AA) genotype. The findings might be influenced by greater cooperation of subjects as they became used to the examination procedure; those with SS and SC disease were photographed on several occasions whereas those with normal haemoglobin genotype were seen only once. Better cooperation could also account for the increasing proportion in whom the border could be photographed as the study progressed, although the proportion in whom the border was photographed did not change in the sickle subjects after the age of 9 years. It is also evident that the degree of pupillary dilatation may influence observation. For this reason the examination was not undertaken until full dilatation was achieved. The procedure limited classification of the vascular border to the temporal retina to reduce variability in the data

That alteration of the vascular border may occur without the vascular pattern changing in designation from type I illustrates the type I border is not always stable in sickle cell disease. This is illustrated further by a postmortem morphological study of an eye from a 20 month old infant with SS disease. ${ }^{16}$ Using adenosine triphosphate labelling of flat retinal vascular preparations, there was good evidence of arteriolar obstruction and consequent loss peripheral retinal capillary bed. In addition, vascular occlusive events are well recorded in early life outside the retina. ${ }^{17}$ These observations collectively indicate that retinal vascular remodelling, which is a 
Figure 14 Left eye in $a$ 9-year-old male with SC disease with a type II a border $(A)$. One year later there was further loss of peripheral vessels, occlusion of a major vessel (arrow), and proliferative disease (B).

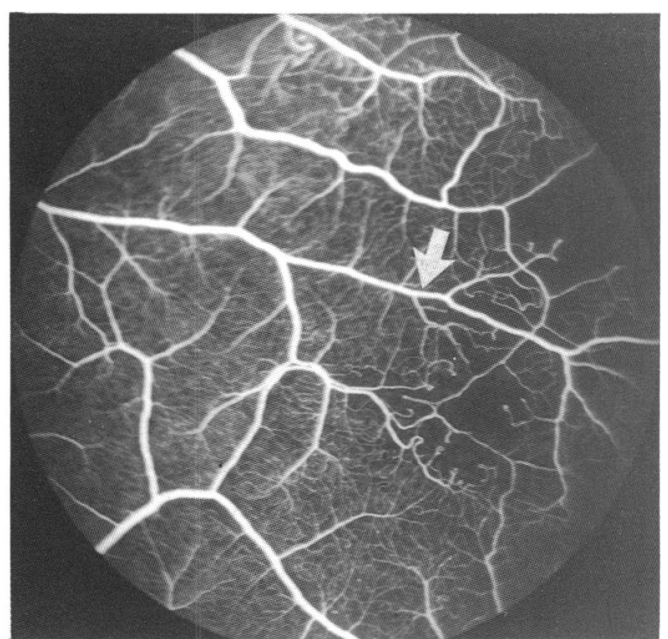

Fig $14 \mathrm{~A}$

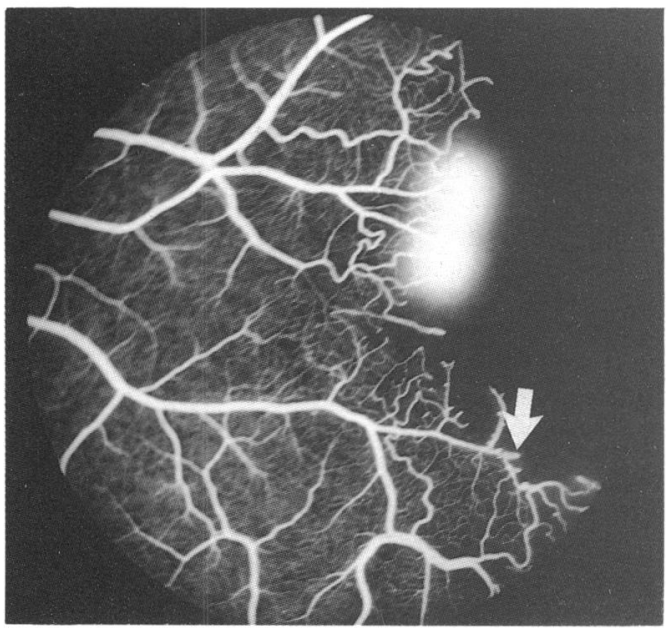

Fig $14 B$

feature of normal early postnatal development, ${ }^{18-21}$ continues well after the age of 6 months in sickle cell disease resulting in posterior displacement of the vascular border. The change would be slow with occasional loss of capillaries at the border of vascular bed or within it. We conclude that the increase of the circumference seen with age and the posterior position of the border in sickle cell disease reflects alteration of the vascular bed rather than an artefact inherent to the study design. Such a gradual evolution appears not to evoke neovascularisation, since a type I border is not associated with proliferative disease however posterior, implying that a posterior border with qualitatively normal perfusion characteristics protects against proliferative disease. The gradual progression of ischaemia may cause loss of viable retina which might otherwise have been the source of diffusible agents causing vasoproliferation.

This slow process can be contrasted with the more radical modification of the vascular pattern giving rise to a type II border. The proportion of eyes that developed PSR in which the anterior border of perfusion was too peripheral to be photographed before the documentation of a type II border is not different from that seen in subjects with normal (AA) haemoglobin genotype, ${ }^{11}$ and is less than that in the whole cohort with sickle cell disease. This indicates that there may have been little modification of the vascular bed before the type II border was recognised, and that conversion occurs in a vascular bed which is relatively unaltered by the sickle cell disease. It follows that the qualitative attributes of the peripheral retinal vasculature in sickle cell disease may reflect the temporal profile of change as much as the presence or absence of change. The higher prevalence of circulatory stasis in subjects who developed a type II border implies that vascular obstruction is important in causing the conversion. The detection of obstructed vessels in $64 \%$ of eyes on at least one occasion, and the short period of vascular stasis in such episodes suggest that this is a very common phenomenon in young individuals with sickle cell disease. It also indicates that the majority of episodes do not result in a major alteration of the capillary bed given the stability of the vascular system in most subjects. Complete reperfusion of the vascular bed has been recorded even following obstruction of large retinal arterioles. ${ }^{22}$

No ready explanation exists for the different temporal profile of retinal vascular changes between $\mathrm{Hb}$ SS disease when compared with $\mathrm{Hb}$ SC, since circulatory stasis was identified in both. The relatively lower figure of detected vascular obstruction in subjects with SS genotype implies that either vascular obstruction is less common or the duration of circulatory disturbance is much shorter in this group. Either alternative could be due to the lower haematocrit which characterises $\mathrm{Hb}$ SS when compared with $\mathrm{Hb}$ SC. This argument has some support in that systemic complications of vascular obstruction are recorded to be more common in subjects with a high haemoglobin and packed cell volume. ${ }^{8} \mathrm{~A}$ higher haemoglobin has been found in subjects with PSR than in those without, although there is some doubt as to whether this was an age dependent relation rather than being a risk factor for PSR.$^{10}$ It is also possible that remodelling of the vascular bed in early life in subjects with $\mathrm{Hb}$ SS giving rise to larger peripheral capillaries at a more posterior locus protects the vascular system from the consequences of vascular obstruction.

Although a type II border was not invariably recorded before development of PSR, the possibility of a change in the vascular bed before the development of PSR cannot be excluded given the frequency of vascular events and the long interval between study visits. In no instance was a type I pattern seen to coexist with PSR in the same region, though rarely other areas of the same eye retained a normal pattern. The demonstration that PSR follows a change of the peripheral vascular organisation, and that this change is associated with SC rather than SS disease accounts for the more serious visual prognosis with this genotype despite the relative mildness of their systemic disease. This has been a dilemma for many years, and the various explanations put forward in the past have not been convincing. It has been suggested that although peripheral non-perfusion, which is the putative stimulus to proliferation, is more common in SS than SC, the frequency of autoinfarction of proliferative complexes in SS disease prevents PSR becoming extensive..$^{22}$ Although this cannot be excluded as a possible protective factor, the data in this study suggest that this is unlikely to 
be the more important determinant of the differential threat to vision in the two genotypes.

We believe that this classification of the peripheral retinal vasculature has potential clinical application in sickle cell retinopathy and is important for screening. Identification of the pattern of the peripheral vasculature allows patients at risk of developing PSR to be identified. A subject with a type I border at a posterior location is most unlikely to develop PSR, whereas the reverse is the case if there are type II characteristics. Perhaps of most importance is the implication that the time course of change in the vascular bed is the major determinant of the observed angioarchitecture, and, therefore, the magnitude of risk of proliferative disease.

We acknowledge the assistance of Mr Rob Acheson, $\mathrm{Mr}$ Brendan Moriarty, and Mr Peter Fox. Statistical calculations were done by Dr J Morris and Dr P Thomas. Film processing and contact printing were done by D Ballantyne.

1 Goldberg MF. Retinal neovascularization in sickle cell retinopathy. Trans Am Acad Ophthalmol Otolaryngol 1977; 83 409-31.

2 Talbot JF, Bird AC, Serjeant GR, Hayes RJ. Sickle cell retinopathy in young children in Jamaica. $\mathrm{Br} \mathcal{F}$ Ophthalmo 1982; 66: 149-54.

3 Talbot JF, Bird AC, Rabb LM, Maude GH, Serjeant GR. Sickle cell retinopathy in Jamaican children - a search for prognostic factors. BrF Ophthalmol 1983; 67: 782-5.

4 Talbot JF, Bird AC, Maude GH, Acheson RW, Moriarty BJ, Serjeant GR. Sickle cell retinopathy in Jamaican children: further observations in a cohort study. $B r f$ Ophthalmo 1988; 72: 727-32.

5 Galinos SO, Asdourian GK, Woolf MB, Stevens TS, Lee CB Goldberg MF, et al. Spontaneous remodelling of the peripheral retinal vasculature in sickling disorders. Am $\mathcal{F}$ Ophthalmol 1975; 79: 853-70.
6 Goldberg MF. Classification and pathogenesis of proliferative sickle retinopathy. Am F Ophthalmol 1971; 71: 649-65.

7 Condon PI, Serjeant GR. Ocular findings in homozygous sickle cell anaemia in Jamaica. Am $\mathcal{F}$ Ophthalmol 1972; 73: 533-43.

8 Serjeant GR. Sickle cell disease. Oxford: Oxford University Press, 1992: Chapter 21, 332.

9 van Meurs JC. Relationship between peripheral vascular closure and proliferative retinopathy in sickle cell disease. closure and proliferative retinopathy in sickle cell
Graefes Arch Clin Exp Ophthalmol 1991; 229: 543-8.

10 Fox PD, Dunn DT, Morris JS, Serjeant GR. Risk factors for proliferative sickle retinopathy. $\mathrm{Br} \mathcal{F}$ Ophthalmol 1990; 74: $172-6$.

11 Penman A, Talbot JF, Chuang EL, Bird AC, Serjeant GR. Peripheral retinal vasculature in normal Jamaican children. Brf Ophthalmol 1994; 78: 615-7.

12 Serjeant GR, Grandison Y, Lowrie Y, Mason K, Phillips J, Serjeant BE, et al. The development of haematological changes in homozygous sickle cell disease; a cohort study from birth to 6 years. Brf Haematol 1981; 48: 533-43.

13 Serjeant GR, Serjeant BE, Forbes $M$, Hayes RJ, Higgs DR Lehman $\mathrm{H}$. Haemoglobin gene frequencies in the Jamaican population: a study in 100,000 newborns. Br $\mathrm{F}$ Haematol population: a study

14 Hamilton AM, Marshall J, Kohner EM, Bowbyes JA. Retinal new vessel formation following experimental vein occlusion. Exp Eye Res 1975; 20: 493-7.

15 Condon PI, Whitelock RAF, Bird AC, Talbot JF, Serjeant GR. Recurrent visual loss in homozygous sickle cell disease. Br f Ophthalmol 1985; 69: 700-6.

16 McLoed GS, Goldberg MF, Lutty GA. Dual-perspective analysis of vascular formations in sickle cell retinopathy. Arch Ophthalmol 1993; 111: 1234-45.

17 Rogers DW, Clarke JM, Ramlal AM, Sparke BR, Serjeant GR. Early deaths in Jamaican children with sickle cell disease. $B M \mathcal{F} 1978 ; 281$ : 1515-6.

18 Ashton N. Studies or the retinal capillaries in relation to diabetic and other retinopathies. BrF Ophthalmol 1963; 47: 22-38.

19 Cogan DG. Development and senescence of the human retinal vasculature. Trans Ophthalmol Soc UK 1965; 83: 465-89.

20 Wise GN, Dollery CT, Henkind P. The retinal circulation. New York: Harper, 1971: 1-18.

21 Foos Y, Kopelow SM. Development of the retinal vasculature in paranatal infants. Clin Path Rev 1973; 18: 117-27.

22 Condon PI, Serjeant GR. Behaviour of untreated proliferative sickle retinopathy. Brf Ophthalmol 1980; 64: 404-11. 